Marquette University

e-Publications@Marquette

Chemistry Faculty Research and Publications

Chemistry, Department of

$1-1-2006$

\title{
A Practical Synthesis of Bridged Diarylacetylenes
}

Ruchi Shukla

Marquette University

Daniel M. Brody

Marquette University

Sergey V. Lindeman

Marquette University, sergey.lindeman@marquette.edu

Rajendra Rathore

Marquette University

Accepted version. The Journal of Organic Chemistry, Vol. 71, No. 16 (2006): 6124-6129. DOI. (C) 2006 American Chemical Society. Used with permission. 


\section{Marquette University \\ e-Publications@Marquette}

\section{Chemistry Faculty Research and Publications/College of Arts and Sciences}

This paper is NOT THE PUBLISHED VERSION; but the author's final, peer-reviewed manuscript. The published version may be accessed by following the link in the citation below.

Journal of Organic Chemistry, Vol. 71, No. 16 (2006): 6124-6129. DOI. This article is (C) American Chemical Society and permission has been granted for this version to appear in ePublications@Marquette. American Chemical Society does not grant permission for this article to be further copied/distributed or hosted elsewhere without the express permission from American Chemical Society.

\section{A Practical Synthesis of Bridged Diarylacetylenes}

Ruchi Shukla

Department of Chemistry, Marquette University, Milwaukee, Wisconsin

Daniel M. Brody

Department of Chemistry, Marquette University, Milwaukee, Wisconsin

Sergey V. Lindeman

Department of Chemistry, Marquette University, Milwaukee, Wisconsin

Rajendra Rathore

Department of Chemistry, Marquette University, Milwaukee, Wisconsin 


\section{Abstract}

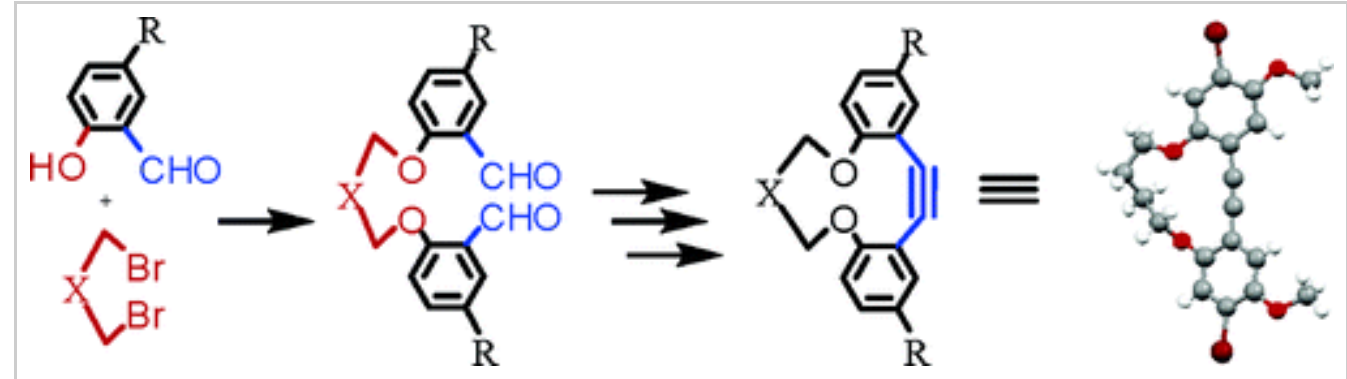

An efficient and practical synthesis of bridged diarylacetylenes in multigram quantities has been successfully carried out using high-yielding (classical) synthetic methods and readily available starting materials. The structural analysis of the representative bridged diarylacetylenes by X-ray crystallography strongly suggests that conformations, bending of the linear triple bond, and the angle between the mean planes of aromatic rings in various bridged diarylacetylenes are governed by the $\mathrm{p}-\pi$ conjugation among the aromatic rings and the ethereal groups. Furthermore, the synthetic scheme also allows the preparation of (appropriately) bromo-substituted bridged diarylacetylenes which hold potential for their future usage for the preparation of polymeric analogues as well as the hexaarylbenzene derivatives for potential applications in the emerging area of molecular electronics and nanotechnology.

\section{Introduction}

The diarylacetylenes are extensively utilized for the preparation of conjugated poly(arylacetylenes) for potential applications in the emerging area of molecular electronics and nanotechnology ${ }^{1}$ as well as for the preparation of nonlinear optical devices and linear chemical probes. ${ }^{2}$ Recently, Bunz et al. have questioned the role of acetylenic $\mathrm{C}$-arene bond rotation on the optoelectronic properties of the diarylacetylenes. ${ }^{3}$ The limited co-planarity of the two aryl groups in various diarylacetylenes can be achieved by tying the aryl groups with the polymethylene bridges of varying lengths (i.e., structure A).

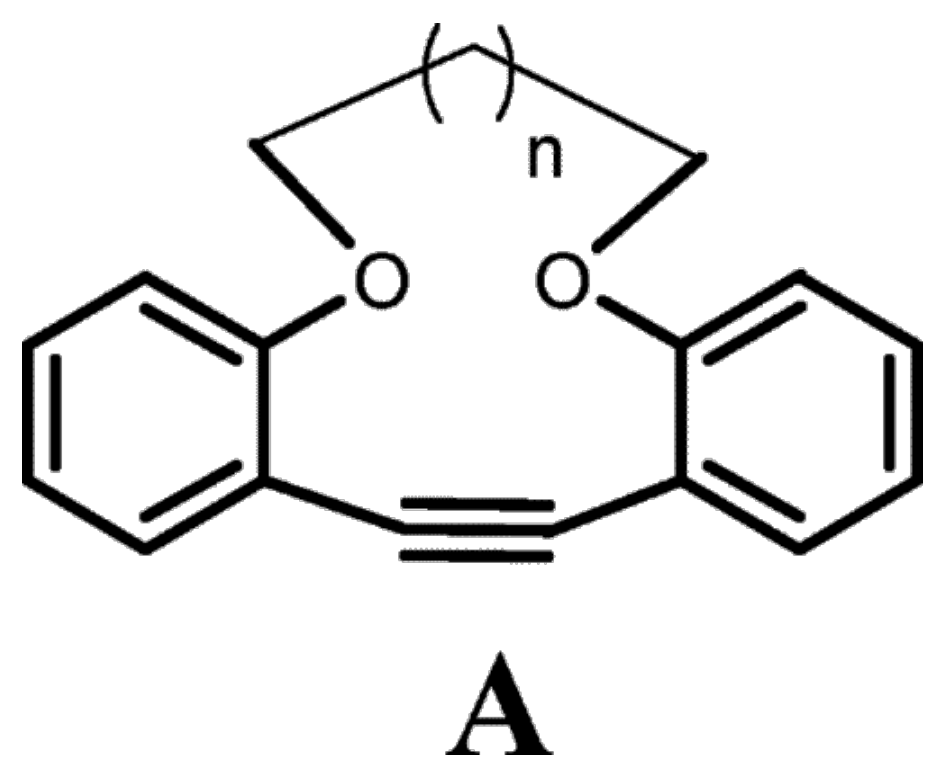


Diarylacetylenes are also important building blocks for the production of hexaarylbenzenes (HAB). It is noteworthy that $\mathrm{HAB}$ derivatives obtained by trimerization of ortho-substituted diarylacetylenes lead to formation of multiple rotamers due to the restricted rotation around the $\mathrm{C}-\mathrm{C}$ bonds between the six peripheral aryl rings and central benzene ring. ${ }^{4}$ Our interest in bridged diarylacetylenes (such as structure $\mathbf{A}$ ) stems from the fact that their trimerization produces only two rotamers which are easily separated by column chromatography. ${ }^{5}$ Thus, a ready access to a variety of bridged diarylacetylenes with different substituents will allow the preparation of substituted HAB derivatives in which the ortho substituents (such as ethereal oxygens; see structure $\mathbf{A}$ ) on the peripheral aryl groups can be directed to one face of the central benzene ring. For example, we have recently demonstrated the potential of one such HAB derivative, containing six ethereal oxygens on one face of the central benzene ring, which allows an effective binding of a single potassium cation via synergistic interactions with the hydrophilic ethereal oxygens and the hydrophobic m-cloud of the central benzene ring via cation-m interaction. ${ }^{5}$ Unfortunately, the synthesis of such bridged diarylacetylenes (see structure A) has been accomplished only in poor yields either via alkyne metathesis ${ }^{3}$ or via a seven-step synthetic route that also required high-dilution conditions and expensive starting materials and catalysts. ${ }^{6}$

Accordingly, herein, we will report a convenient and efficient route for the preparation of multigram quantities of bridged diarylacetylenes from the readily available salicylaldehydes using high-yielding (classical) synthetic methods. For example, two salicylaldehyde moieties are readily connected to a desired bridge by nucleophilic substitution reaction followed by intramolecular McMurry coupling to form bridged stilbenes which, in turn, are easily transformed to the corresponding bridged diarylacetylenes via a bromination/dehydrobromination sequence. The generality of the synthetic scheme for the preparation of various bridged diarylacetylenes and the X-ray structures/conformations of representative diarylacetylenes will be discussed.

\section{Results and Discussion}

Thus, salicylaldehyde $(0.2 \mathrm{~mol})$ was reacted with ethanolic potassium hydroxide $(0.2 \mathrm{M}, 200$ $\mathrm{mL}$ ) at reflux to form a bright yellow solution of potassium salt of salicylaldehyde, which was then reacted with 1,4-dibromobutane $(0.095 \mathrm{~mol})$ to afford bridged dialdehyde $1 \mathrm{a}$ as crystalline solid in $>95 \%$ yield (eq 1 ). 


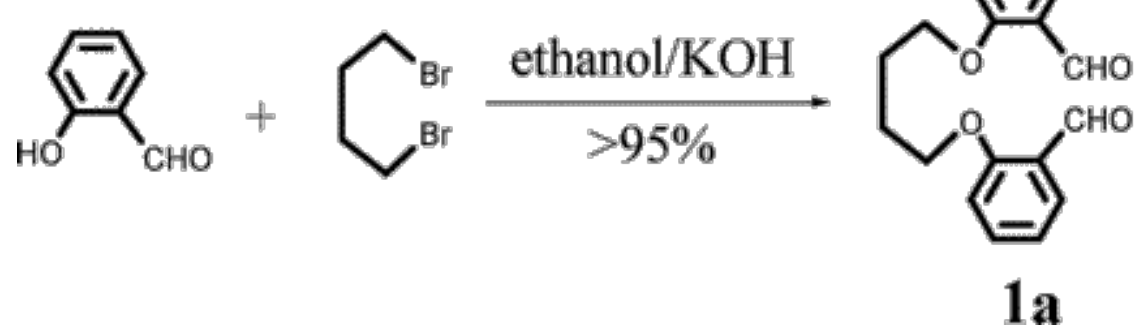

An intramolecular McMurry coupling of the above dialdehyde 1a, under mild dilution, produced a mixture of cis/trans stilbenes $\mathbf{2} \mathbf{a}$ in $>90 \%$ yield. For example, a solution of $\mathbf{1 a}(23.9 \mathrm{~g}, 0.08$ $\mathrm{mol}$ ) in tetrahydrofuran $(500 \mathrm{~mL}$ ) was added slowly during the course of $48 \mathrm{~h}$ to a refluxing slurry of $\mathrm{TiCl}_{4}-\mathrm{Zn}$ in tetrahydrofuran $(1 \mathrm{~L})$ containing a catalytic amount of dry pyridine, and the resulting slurry was refluxed for an additional $12 \mathrm{~h}$. A standard aqueous workup followed by column chromatography afforded the bridged stilbene $2 \mathrm{a}$ as a viscous oil in $>90 \%$ yield. Note that $\sim 5 \%$ of stilbenophane ${ }^{7}$ (see structure B) was also produced via a McMurry coupling of the two molecules of $1 \mathbf{a}$ (eq 2).

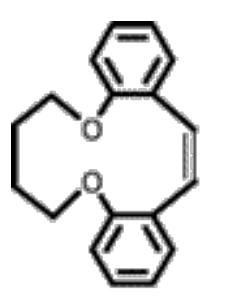

2a (a)

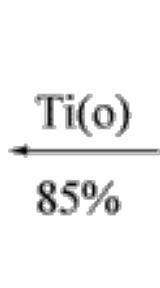

1 a

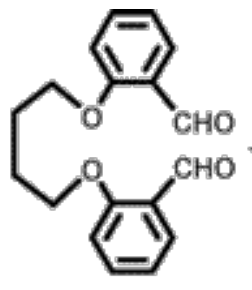

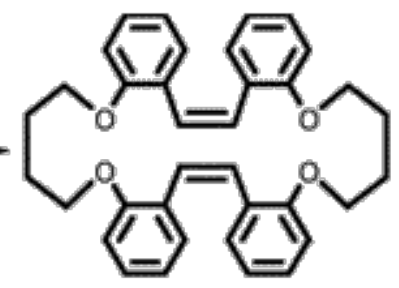

B

(2)

The ${ }^{1} \mathrm{H} /{ }^{13} \mathrm{C}$ NMR spectroscopic data coupled with mass spectroscopic analysis clearly indicated that the stilbenophane $\mathbf{B}$ consisted of a mixture of all three isomers, that is, an isomer containing cis-cis stilbene moieties (cis-cis B), an isomer containing trans-trans stilbene moieties (trans-transB), and a minor isomer containing cis-trans stilbene moieties (cis-trans $\mathbf{B}$ ), which could not be separated by column chromatography. ${ }^{7}$ However, repeated attempts of crystallizations from dichloromethane/hexane mixtures yielded a small amount of needleshaped crystals that were subjected to crystallographic analyses. The X-ray structure analysis confirmed the structure of the preferentially crystallized stilbenophane isomer to be transtrans $\mathbf{B}$, as shown in the Figure S1. Moreover, hitherto unknown stilbenophane $\mathbf{B}$ possesses an "L-shaped" conformation due to a strong preference for the ethereal groups to lie in the aromatic planes (see Figure S1 in the Supporting Information). It is conceivable that the unique shape of the electron-rich stilbenophane $\mathbf{B}$ and its derivatives may lead to the design and syntheses of a variety of supramolecular architectures for potential applications in the emerging area of molecular electronics and nanotechnology. 
A reaction of the mixture of cis/trans stilbenes $\mathbf{2 a}$, obtained above, with 1 equiv of bromine in acetic acid or dichloromethane at $0^{\circ} \mathrm{C}$ produced a complex mixture of products, which upon NMR spectroscopic analysis indicated that $\mathbf{2 a}$ was (partially) brominated both at the double bond as well as at the aromatic rings due to the presence of free (activated) positions para to the alkoxy groups. Indeed, in another reaction, treatment of $\mathbf{2 a}(13.3 \mathrm{~g}, 50 \mathrm{mmol})$ with 3.2 equiv of bromine in acetic acid produced quantitatively a stereoisomeric mixture of tetrabromo derivative $\mathbf{3 a}$ (eq 3 ).

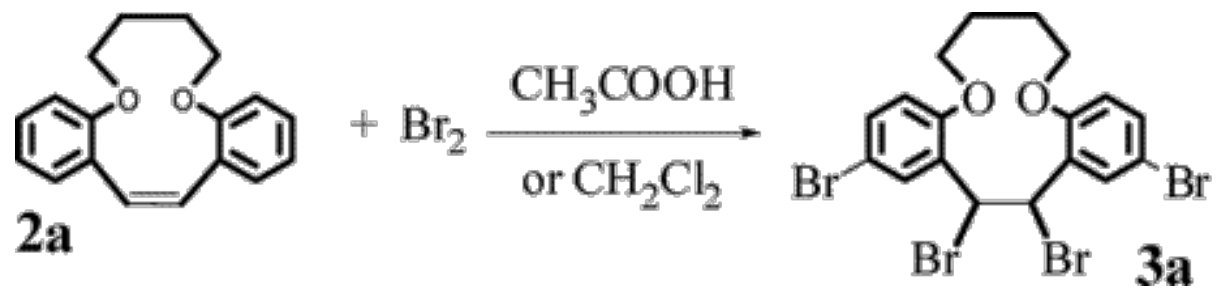

The tetrabromo derivative 3a was subjected, without any purification, to a dehydrobromination reaction in ethylene glycol containing $\mathrm{KOH}$ at $\sim 190{ }^{\circ} \mathrm{C}$ for 5 min to afford the bridged diarylacetylene $\mathbf{4 a}$ in $>90 \%$ yield after chromatographic purification (eq 4 ).

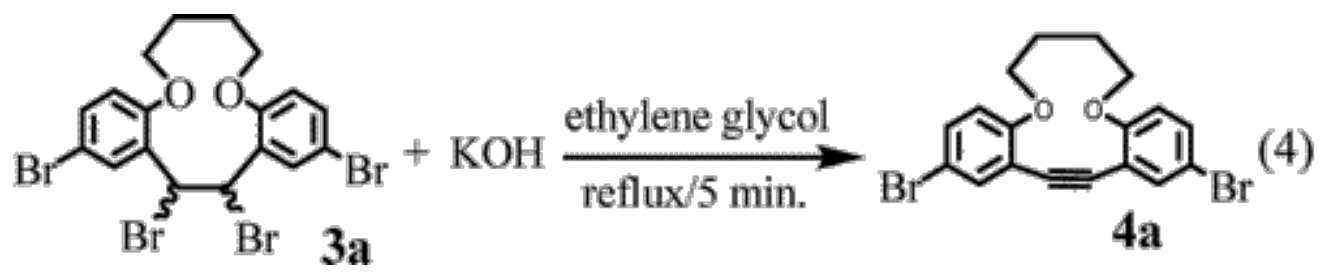

It is important to note that the bromination/dehydrobromination sequence described in eqs 3 and 4 was also carried out with the crude stilbene $\mathbf{2 a}$ (from eq 2 ) without any substantial loss in the yield of the desired acetylene $4 a$. Thus, the reaction sequence described in eqs 1-4 can be utilized for the preparation of a 10-20 g scale of the bridged diarylacetylene $\mathbf{4 a}$ (in $~ 70 \%$ over all yield) without the need for column chromatographic purification of any of the intermediates in eqs $1-4$. Structure of the bridged diarylacetylene $4 \mathrm{a}$ was readily established by ${ }^{1} \mathrm{H} /{ }^{13} \mathrm{C} N M R$ spectroscopy, GC-MS, correct elemental analysis, and by X-ray crystallography (vide infra).

Encouraged by the success of the reaction sequence in eqs 1-4 for the preparation of $4 a$, we applied the same synthetic strategy to a variety of substituted salicylaldehydes, as summarized in Scheme 1. Indeed, the generality of the strategy in Scheme 1 was established by a successful completion of the synthesis of various bridged diarylacetylenes $\mathbf{4 b - f}$ in excellent yields, as summarized in Table 1 . The structures of bridged diarylacetylenes $\mathbf{4 b} \mathbf{b} \mathbf{f}$ were established by ${ }^{1} \mathrm{H} /{ }^{13} \mathrm{C}$ NMR spectroscopy, GC-MS, correct elemental analysis, and by X-ray crystallography of the representative examples (vide infra). 

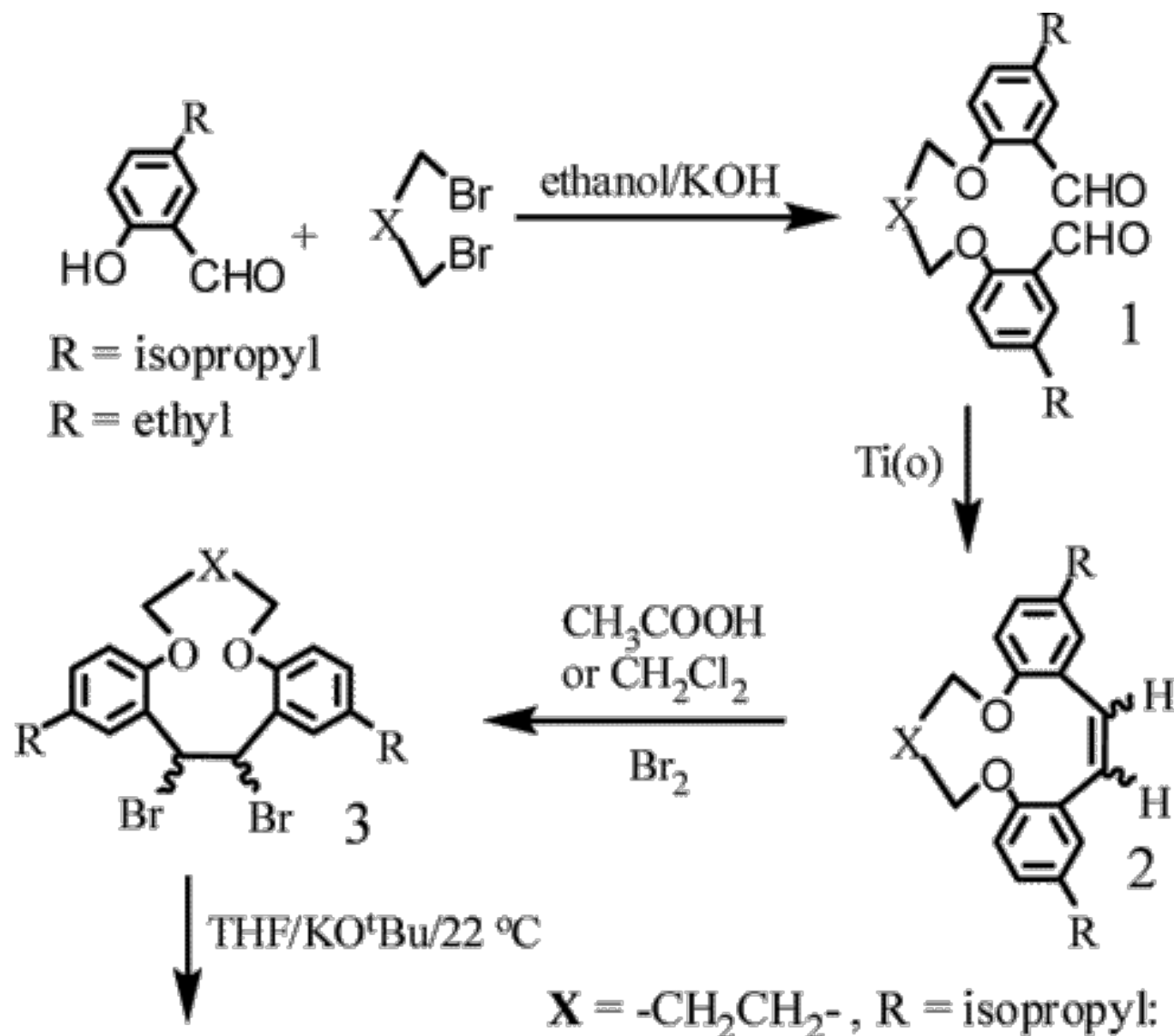

$2^{\circ} \mathrm{C}$
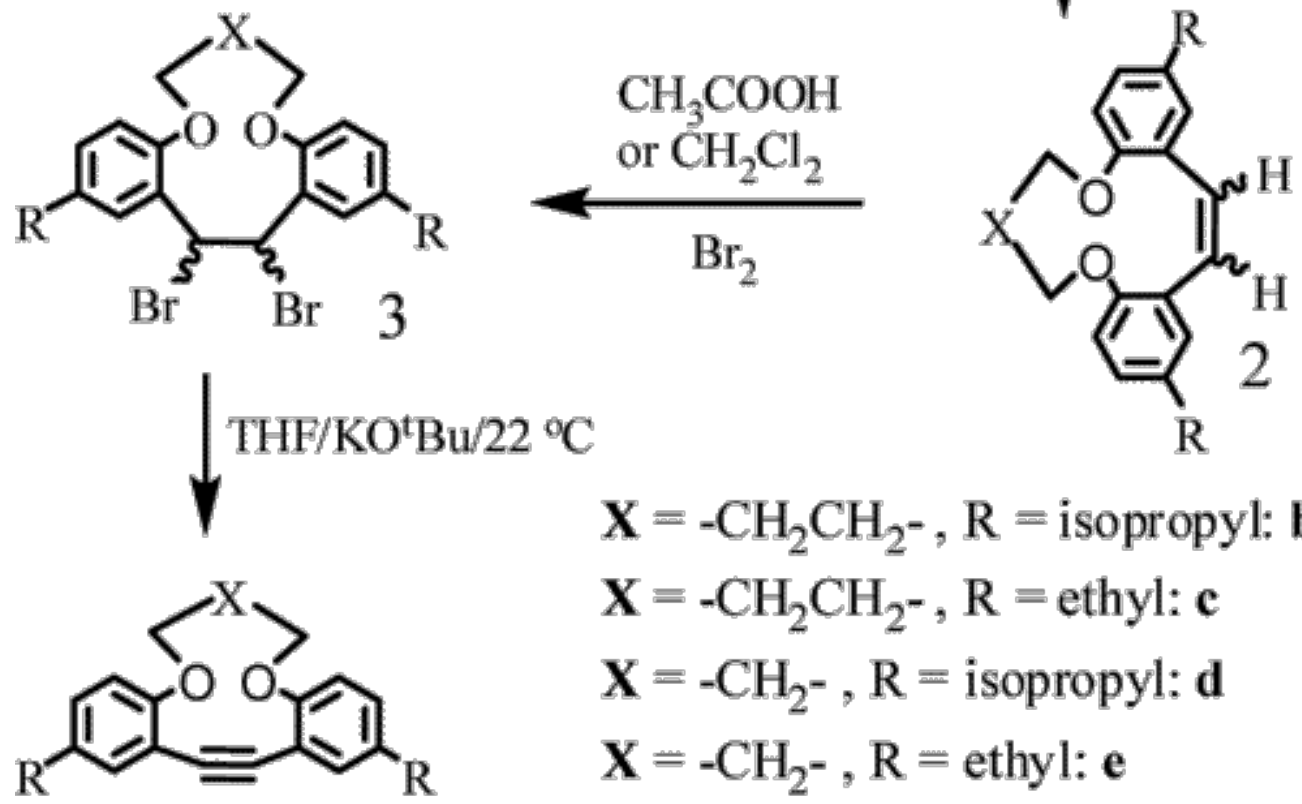

$$
\begin{aligned}
& \mathbf{X}=-\mathrm{CH}_{2} \mathrm{CH}_{2^{-}}, \mathrm{R}=\text { isopropyl: } \mathbf{b} \\
& \mathbf{X}=-\mathrm{CH}_{2} \mathrm{CH}_{2^{-}}, \mathrm{R}=\text { ethyl: } \mathbf{c} \\
& \mathbf{X}=-\mathrm{CH}_{2^{-}}, \mathrm{R}=\text { isopropyl: } \mathbf{d} \\
& \mathbf{X}=-\mathrm{CH}_{2^{-}}, \mathrm{R}=\text { ethyl: } \mathbf{e}
\end{aligned}
$$

4

Scheme 1. A Generalized Scheme for the Bridged Diarylacetylene Synthesis Table 1. Yields of Various Intermediates and Bridged Diarylacetylenes 


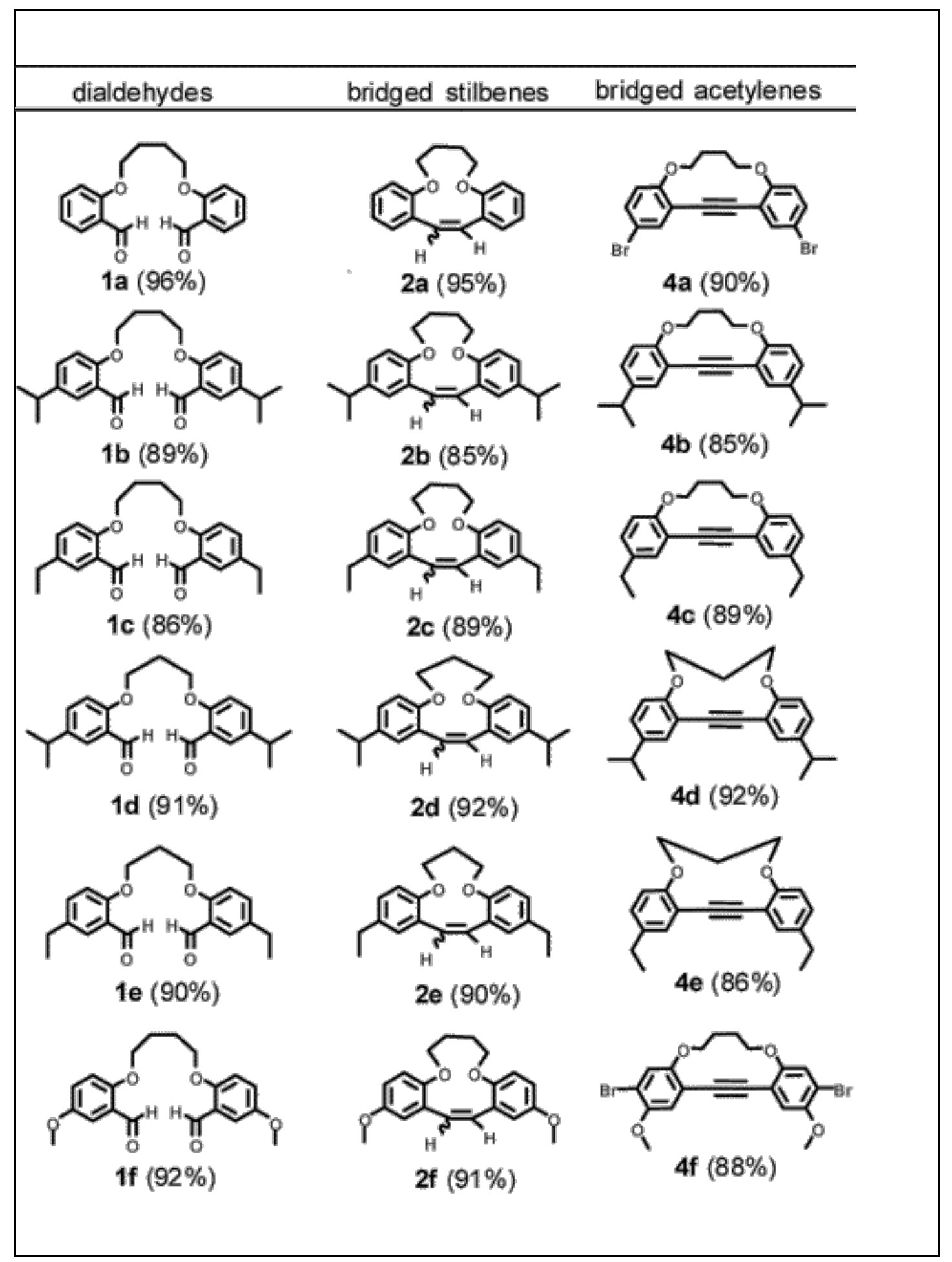

The important features of the reaction sequence in Scheme 1 are summarized below. (i) The successful (high-yielding) dehydrobromination reaction in eq 4, using ethylene glycol/KOH for the preparation of $\mathbf{4 a}$, unfortunately afforded a mixture of products when applied to the dibromo derivative $\mathbf{3 b}$. A careful chromatographic separation afforded only a 
trace amount $(<5 \%)$ of the desired acetylene $\mathbf{4 b}$ together with an unexpected (major) product $\mathbf{C}$ in $>30 \%$ (unoptimized) yield (eq 5 ).

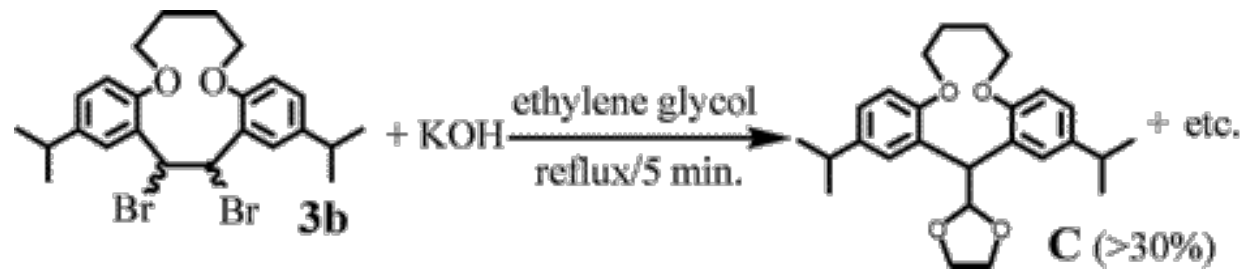

The structure of major product $\mathbf{C}$ was established by ${ }^{1} \mathrm{H} /{ }^{13} \mathrm{C}$ NMR spectroscopy, GC-MS, and was further confirmed by X-ray crystallography (see Figure S2 in the Supporting Information). The formation of rearranged acetal $\mathbf{C}$ during the dehydrobromination of $\mathbf{4 b}$ in eq 5 is unprecedented, and the mechanism of its formation will require additional investigations. ${ }^{8}$

(ii) It is conceivable that the rearrangement problem encountered in eq 5 may be responsible for the sparse usage of the bromination/dehydrobromination sequence for the preparation of diarylacetylenes from the readily available stilbenes! The rearrangement problem, however, was completely avoided if the dehydrobromination reaction was carried out using potassium tert-butoxide in tetrahydrofuran at $22^{\circ} \mathrm{C}$. Indeed, all of brominated stilbenes in Table 1 afforded the corresponding bridged diarylacetylenes $\mathbf{4 a - f}$ in excellent yields using $\mathrm{K}^{\mathrm{t}} \mathrm{OBu} / \mathrm{THF}$ at $22^{\circ} \mathrm{C}$.

(iii) It is important to emphasize that the reactions of stilbenes $\mathbf{2} \mathbf{b}-\mathbf{e}$ with bromine in dichloromethane (or acetic acid) did not show any sign of bromination of the aromatic rings because of the fact that (activated) positions para to alkoxy groups were blocked by the alkyl substituents. However, the last entry in the Table 1, where 5-methoxysalicylaldehyde was utilized as the starting material, expectedly produced the ring-brominated bridged diarylacetylene $\mathbf{4 f}$ in which the ring bromines were introduced exclusively para to the stilbenoid carbons (eq 6).

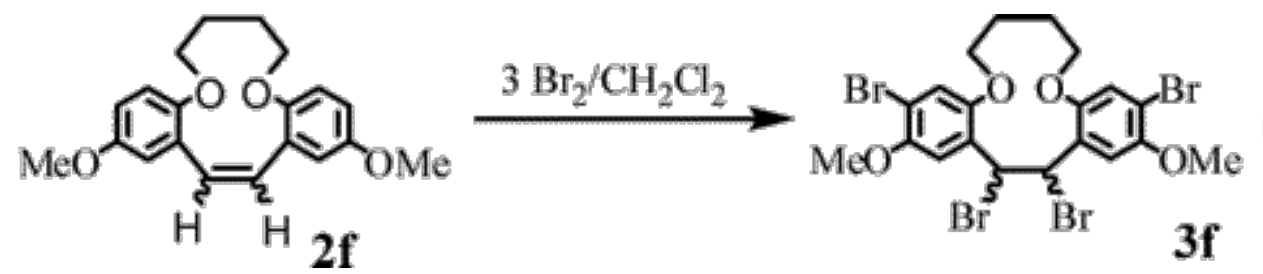

Note that the positions of ring bromination in $3 \mathrm{f}$ in eq 6 are analogous to that observed for the bromination of 2,5-dialkoxytoluene in which the electrophilic substitutions occur para to the alkyl substituents. ${ }^{9}$

(iv) Importantly, the ring-brominated diarylacetylenes $\mathbf{4 a}$ and $\mathbf{4 f}$ can be easily debrominated by reaction with magnesium in tetrahydrofuran followed by treatment with water to 
produce $\mathbf{4 g}$ and $\mathbf{4 h}$ in quantitative yields (eqs 7 and $\mathbf{8}$, and see the Supporting Information for the experimental details). Moreover, the readily available diarylacetylenes $\mathbf{4 a}$ and $\mathbf{4 f}$ form the synthetic strategy in Scheme 1 and hold potential to be utilized for the preparation of a variety of new substituted bridged diarylacetylene as well as electro-active materials by usage of versatile palladium-and nickel-catalyzed $\mathrm{C}-\mathrm{C}$ bond-forming reactions. ${ }^{10}$

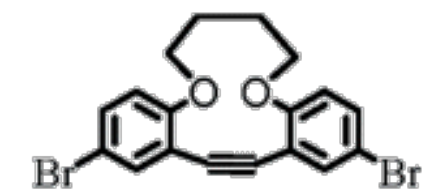

$4 \mathbf{a}$

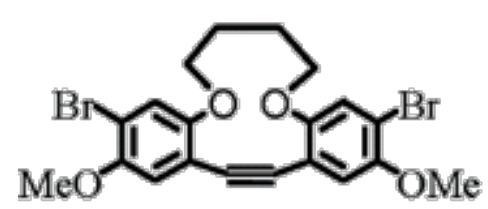

$4 \mathbf{f}$

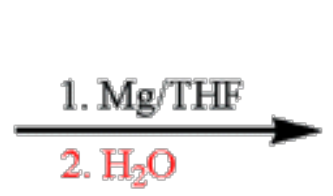

2. $\mathrm{H}_{2} \mathrm{O}$

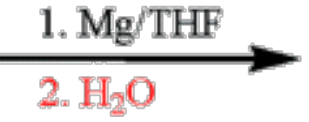

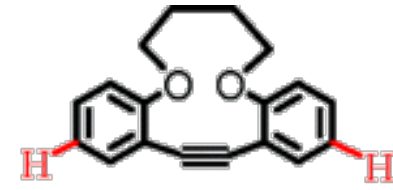

$4 \mathrm{~g}$

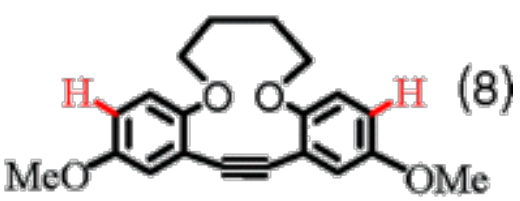

4h

X-ray Crystallography. The molecular structures of the representative bridged

diarylacetylenes (i.e., $\mathbf{4 a}, \mathbf{4 d}$, and $\mathbf{4 f}$ ) were determined by X-ray crystallography to probe the conformational characteristics of bridged diarylacetylenes in Table 1. Two conformational views of the molecular structures of $\mathbf{4 a}, \mathbf{4 d}$, and $\mathbf{4} \mathbf{f}$ are displayed in Figure 1 , and the critical structural features that control the conformations of the central 11-membered ring in $\mathbf{4 d}$ and 12-membered rings in $\mathbf{4 a}$ and $\mathbf{4} \mathbf{f}$ are briefly discussed below.
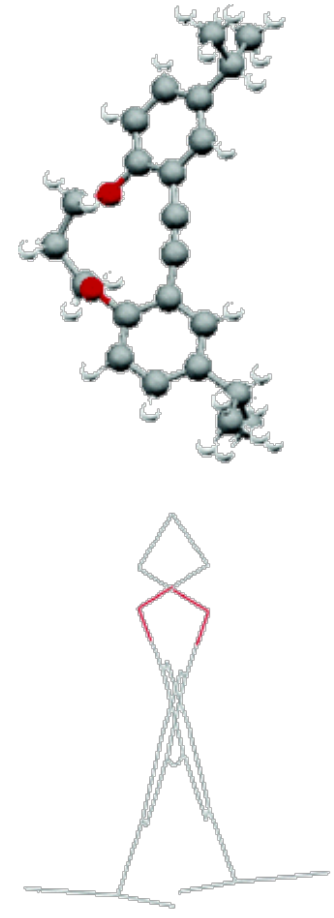

4d
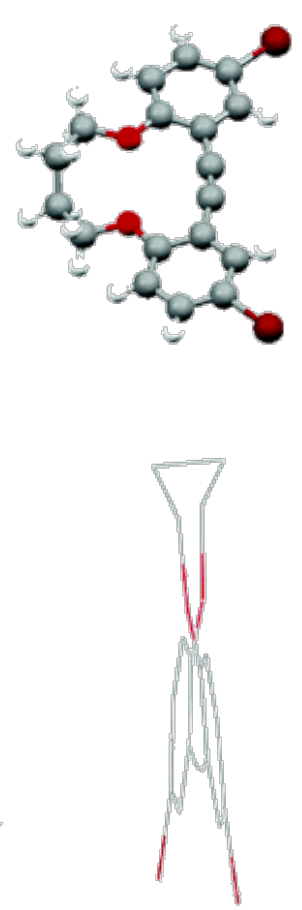

$4 a$
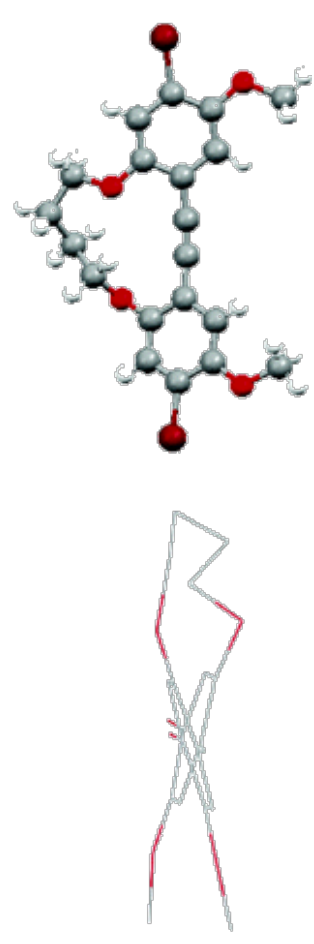

4f 
Figure 1 Molecular structures of $\mathbf{4 a}, \mathbf{4 d}$, and $\mathbf{4 f}$ represented as ball-and-stick and line diagrams showing different views.

We believe that the most important factor that controls the conformations of $\mathbf{4 a}, \mathbf{4 d}$, and $\mathbf{4 f}$ is the $p-\pi$ conjugation between the aromatic rings and the ethereal groups. It is well-recognized that in the absence of the steric encumbrances the ethereal groups in aryl alkyl ethers lie in the aromatic planes (i.e., dihedral angle $\sim 0^{\circ}$ ). ${ }^{11}$ However, the size of the trimethylene bridge in $\mathbf{4} \mathbf{d}$ between the ethereal oxygens is too large to allow a cis-periplanar conformation and too short to allow a trans-periplanar arrangement. As a result, the diarylacetylene moiety adopts a twisted conformation with an angle of $\sim 30^{\circ}$ between the mean planes of the aromatic ring (around a crystallographic 2-fold axis), where $-\mathrm{O}-\mathrm{CH}_{2}-$ groups are turned in opposite directions and lie almost perpendicular to the aromatic planes (dihedral angle $\sim 81.6^{\circ}$ ). The apparent loss of $\mathrm{p}-\mathrm{T}$ conjugation results in elongated $\mathrm{C}(\mathrm{ar})-\mathrm{O}$ bonds $(1.375 \AA)$ and more "sp ${ }^{3}$ like" values of the $\mathrm{C}-\mathrm{O}-\mathrm{C}$ bond angles $\left(113.8^{\circ}\right)$.

A longer tetramethylene bridge in molecule $\mathbf{4 a}$ accommodates the trans-periplanar arrangement of its ethereal linkages which allows $-\mathrm{O}-\mathrm{CH}_{2}-$ groups to lie in the aromatic planes (dihedral angles $<4^{\circ}$ ). The trans-periplanar conformation in $\mathbf{4 a}$ leads to an effective $\mathrm{p}-\pi$ conjugation that results in shortened $\mathrm{C}(\mathrm{ar})-\mathrm{O}$ bonds $(1.351 \AA)$ and more $\mathrm{sp}^{2}$-like $\mathrm{C}-\mathrm{O}-\mathrm{C}$ bond angles $\left(119.1^{\circ}\right)$. Moreover, the diarylacetylene moiety in $4 \mathrm{a}$ adopts a conformation in which the angle between the mean planes of benzene rings is only $\sim 9^{\circ}$. However, such a trans-periplanar conformation and a co-planar arrangement of the aryl groups in $\mathbf{4 a}$ comes at a price; that is, the tetramethylene bridge is forced into an unfavorable (eclipsed) conformation with the central $\mathrm{C}-\mathrm{C}-\mathrm{C}-\mathrm{C}$ dihedral angle of $113^{\circ}$, and it also causes a bend in the acetylenic triple bond by $\sim 19^{\circ}$ compared to $12^{\circ}$ in $\mathbf{4 d}$.

Interestingly, however, the X-ray structure of $\mathbf{4 f}$, with a tetramethylene bridge akin to that in $\mathbf{4 a}$, showed that it exists in an asymmetric conformation in which one of the ethereal groups lies perpendicular to the aromatic plane (i.e., dihedral angle $\sim 76.7^{\circ}$, an elongated $\mathrm{C}(\mathrm{ar})-\mathrm{O}$ bond, $1.382 \AA$, and a contracted $\mathrm{C}-\mathrm{O}-\mathrm{C}$ angle of $\left.114.5^{\circ}\right)$, whereas the other ethereal group lies in a quasi-trans-periplanar conformation (i.e., dihedral angle of $34.4^{\circ}$, a shortened $\mathrm{C}(\mathrm{ar})-\mathrm{O}$ distance, $1.364 \AA$, and a more opened $\mathrm{C}-\mathrm{O}-\mathrm{C}$ angle of $118.2^{\circ}$ ). Importantly, the asymmetric conformational arrangement in $\mathbf{4 f}$ leads to a more linear central $-\mathrm{C}: \mathrm{C}$ - triple bond; that is, it is bent by just $\sim 10^{\circ}$ in comparison to that in $4 \mathrm{a}$, where it is bent by $\sim 19^{\circ}$ (see Figure 1 ). In conclusion, the bending of the linear central $-\mathrm{C}: \mathrm{C}-$ triple bond as well as the twist angle between the mean planes of aromatic rings in $\mathbf{4 d}, \mathbf{4 a}$, and $\mathbf{4 f}$ is controlled by the conformations 
of 11- and 12-membered rings, which in turn are largely governed by the $p-\pi$ conjugation among the aromatic rings and the ethereal groups. ${ }^{12}$

\section{Summary}

In summary, a successful synthesis of various bridged diarylacetylenes in multigram quantities has been accomplished using high-yielding (classical) synthetic methods and readily available starting materials. The structures of representative bridged diarylacetylenes have been established by $\mathrm{X}$-ray crystallography. The structural analysis strongly indicates that the conformations of 11- and 12-membered rings in various bridged diarylacetylenes are largely controlled by the $p-\pi$ conjugation among the aromatic rings and the ethereal groups and that, in turn, controls the bending of the linear triple bond as well as the twist angle between the mean planes of aromatic rings.

The ready availability of bromo-substituted bridged diarylacetylenes $\mathbf{4 a}$ and $\mathbf{4 f}$ holds potential to be utilized for the preparation of a variety of electro-active materials by modern palladiumand nickel-catalyzed $\mathrm{C}-\mathrm{C}$ bond-forming reactions. We are presently exploring the preparation of polymeric analogues of $\mathbf{4 a}$ and $\mathbf{4} \mathbf{f}$ and the hexaarylbenzene derivatives via trimerization of various bridged diarylacetylenes for potential applications in the emerging area of molecular electronics and nanotechnology.

\section{Experimental Section}

Preparation of Bridged Dialdehydes 1a-f. Thus, following closely a literature procedure, ${ }^{14}$ an addition of salicylaldehyde $(24.4 \mathrm{~g}, 0.2 \mathrm{M})$ to an ethanolic solution (200 mL) of potassium hydroxide $(11.2 \mathrm{~g}, 0.2 \mathrm{~mol})$ immediately resulted in a yellow precipitate of the potassium salt of salicylaldehyde which dissolved upon further refluxing. 1,4-Dibromobutane $(20.5 \mathrm{~g}, 0.095 \mathrm{~mol}$ ) was added dropwise to the above reaction mixture, and the resulting mixture was refluxed for additional 8-12 h. Upon cooling, the resulting mixture just below the boiling point of ethanol and a rapid filtration produced a clear solution which upon standing at room temperature produced a mass of pale yellow crystals. The crystalline mass was filtered and washed with a mixture of cold ethanol and water $(1: 1,50 \mathrm{~mL})$. Another recrystallization of the resulting solid from ethanol afforded $1 \mathrm{a}$ as a colorless crystalline solid. Yield: $28.7 \mathrm{~g}, 96 \%$; mp106-108 ${ }^{\circ} \mathrm{C}$ (lit. $\left.{ }^{14} \mathrm{mp} 84{ }^{\circ} \mathrm{C}\right) ;{ }^{1} \mathrm{H}$ NMR $\left(\mathrm{CDCl}_{3}\right) \delta 2.06(\mathrm{~m}, 4 \mathrm{H}), 4.16(\mathrm{~m}, 4 \mathrm{H}), 6.97(\mathrm{~m}, 4 \mathrm{H})$,

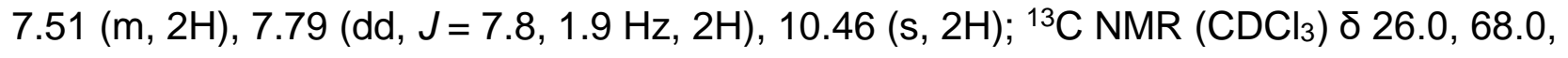
112.5, 120.8, 124.9, 128.5, 128.6, 136.2, 161.3, 189.7. GC-MS: $\mathrm{m} / \mathrm{z} 298\left(\mathrm{M}^{+}\right), 298$ calcd for 
$\mathrm{C}_{18} \mathrm{H}_{18} \mathrm{O}_{4}$. Anal. Calcd for $\mathrm{C}_{18} \mathrm{H}_{18} \mathrm{O}_{4}: \mathrm{C}, 72.47 ; \mathrm{H}, 6.08$. Found: $\mathrm{C}, 72.45 ; \mathrm{H}, 6.06$. The yields and the spectral data for $\mathbf{1 b} \mathbf{b} \mathbf{f}$ are summarized in the Supporting Information.

Preparation of Bridged cis/trans Stilbene 2a-h. ${ }^{15}$ General Procedure. To chilled $\left(\sim 0{ }^{\circ} \mathrm{C}\right)$ anhydrous tetrahydrofuran $(1 \mathrm{~L})$ was added $\mathrm{TiCl}_{4}(30 \mathrm{~mL}, 270 \mathrm{mmol})$ dropwise with the aid of a dropping funnel under an argon atmosphere. To the resulting mixture were added $\mathrm{Zn}$ dust (22 $\mathrm{g}, 340 \mathrm{mmol}$ ) and dry pyridine ( $1 \mathrm{~g}, 13 \mathrm{mmol})$, and the resulting black suspension thus obtained was warmed to room temperature and then refluxed for $2 \mathrm{~h}$. A solution of dialdehyde $1 \mathrm{a}(23.87 \mathrm{~g}, 80 \mathrm{mmol})$ in THF $(500 \mathrm{~mL})$ was added dropwise to the above black reaction mixture during a course of $48 \mathrm{~h}$ while refluxing, and the resulting mixture was refluxed for an additional $12 \mathrm{~h}$. The resultant mixture was cooled to room temperature and quenched with $10 \%$ aqueous $\mathrm{K}_{2} \mathrm{CO}_{3}(300 \mathrm{~mL})$. The organic layer was separated, and the aqueous suspension was extracted with dichloromethane $(5 \times 150 \mathrm{~mL})$ followed by diethyl ether $(3 \times$ $100 \mathrm{~mL}$ ). The combined organic layers were dried over anhydrous $\mathrm{MgSO}_{4}$, filtered, and evaporated to afford a syrupy liquid which was purified by flash chromatography on silica gel using a 1:9 mixture of ethyl acetate and hexanes to afford a mixture of cis/trans stilbene $\mathbf{2} \mathbf{a}$ as a viscous oil.

Note that attempts to separate cis/trans isomers of various stilbenes, in most cases, were not successful. However, in most cases, the integration of the peaks in the aliphatic region allowed the ratios of the two isomers to be determined; however, the identity of the isomers (i.e., whether it is cis or trans) could not be established due to the extensive overlap of the signals in the aromatic/olefinic region. Accordingly, the spectral data for various bridged stilbenes in the aliphatic region are readily deconvoluted, whereas in the aromatic/olefinic region, they are presented as ranges. The number of signals in the ${ }^{13} \mathrm{C}$ NMR spectra are in complete agreement with the assignment that the bridged stilbenes exist as isomeric (cis/trans) mixtures. 2a: Yield $20.2 \mathrm{~g}, 95 \%$ (ratio of isomers I and II = 2:1). Isomer I: ${ }^{1} \mathrm{H} N M R\left(\mathrm{CDCl}_{3}\right) \delta$ 1.76 (sym m, 4H), 4.04 (sym m, 4H), 6.65-7.42 (aromatic/olefinic, 10H). Isomer II: 2.01 (sym $\mathrm{m}, 4 \mathrm{H}$ ), 4.11 (sym m, 4H), 6.65-7.42 (aromatic/olefinic, $10 \mathrm{H}$ ); ${ }^{13} \mathrm{C} \mathrm{NMR}\left(\mathrm{CDCl}_{3}\right) \delta$ 26.1, 26.2, 69.4, 71.9, 114.6, 118.3, 120.6, 122.9, 127.8, 128.2, 128.3, 129.0, 129.4, 130.0, 130.5, 155.5, 157.8. GC-MS: $m / z 266\left(\mathrm{M}^{+}\right), 266$ calcd for $\mathrm{C}_{18} \mathrm{H}_{18} \mathrm{O}_{2}$. The spectral data of $\mathbf{2 b - f}$ are summarized in the Supporting Information. [Also, note that various stilbenes obtained above were used in the next step without any further purification.]

Preparation of Bridged Diarylacetylenes. To a solution of a cis/trans mixture of stilbene $2 \mathbf{a}(13.3 \mathrm{~g}, 50 \mathrm{mmol})$ in acetic acid $(50 \mathrm{~mL})$ was added dropwise a solution of bromine $(26.4 \mathrm{~g}, 165 \mathrm{mmol})$ in acetic acid $(50 \mathrm{~mL})$ at $22^{\circ} \mathrm{C}$. The reaction mixture was stirred for $30 \mathrm{~min}$ 
and was poured into water $(250 \mathrm{~mL})$. The resulting mixture was extracted with dichloromethane $(3 \times 100 \mathrm{~mL})$, washed with $10 \%$ aqueous sodium bisulfite $(2 \times 50 \mathrm{~mL})$, and dried over anhydrous $\mathrm{MgSO}_{4}$. Evaporation of the solvent afforded a quantitative yield of the corresponding tetrabromostilbene $\mathbf{3 a}$, which was used in the next step without further purification as follows. [Note that bromination of stilbenes $\mathbf{2} \mathbf{b}-\mathbf{e}$ required only 1 equiv of bromine, while the bromination of $2 \mathrm{f}$ required 3 equiv of bromine, and the reactions can be carried out in either acetic acid or dichloromethane as solvent; see text.]

Dehydrobromination using Ethylene glycol/KOH. Tetrabromostilbene derivative $3 a$ ( $9 \mathrm{~g}$, $0.015 \mathrm{mmol})$, ethylene glycol $(30 \mathrm{~mL})$, and $\mathrm{KOH}(5 \mathrm{~g})$ were placed in a round-bottom flask fitted with a condenser. The resulting mixture was heated to reflux for 5 min then cooled to room temperature and was diluted with water $(200 \mathrm{~mL})$. A standard aqueous workup and purification by flash chromatography (silica gel, 10:90 mixture of ethyl acetate:hexanes as eluent) afforded pure diarylacetylene $\mathbf{4 a}$ as crystalline solid.

Dehydrobromination Using KO'Bu/THF. To a solution of dibromostilbene $3 \mathbf{b}$ ( $25.5 \mathrm{~g}, 50$ $\mathrm{mmol})$ in dry tetrahydrofuran $(200 \mathrm{~mL})$ was added, in portions, potassium $t$-butoxide $(12.4 \mathrm{~g}$, $110 \mathrm{mmol}$ ), and the resulting mixture was stirred at $22^{\circ} \mathrm{C}$ for $2 \mathrm{~h}$. A standard aqueous workup and purification by flash chromatography (silica gel, 10:90 mixture of ethyl acetate:hexanes as eluent) afforded pure diarylacetylene $\mathbf{4 b}$ as a viscous oil. $\mathbf{4 b}$ : Yield $14.8 \mathrm{~g}, 85 \%$ (viscous oil); ${ }^{1} \mathrm{H}$ NMR ( $\left.\mathrm{CDCl}_{3}\right) \delta 1.23$ (d, $\mathrm{J}=6.7 \mathrm{~Hz}, 12 \mathrm{H}$ ), 2.05 (sym m, 4H), 2.85 (septet, $\mathrm{J}=6.7 \mathrm{~Hz}$, 2H), 4.24 (sym m, 4H), 6.85 (d, J = 8.3 Hz, 2H), 7.1 (dd, J = 8.3, 2.4 Hz, 2H), $7.3(\mathrm{~d}, J=2.4$ $\mathrm{Hz}, 2 \mathrm{H}) ;{ }^{13} \mathrm{C} \mathrm{NMR}\left(\mathrm{CDCl}_{3}\right) \delta 24.3,26.7,33.5,71.4,91.8,115.1,116.3,127.8,129.4,142.4$, 159.4. GC-MS: $m / z 348\left(\mathrm{M}^{+}\right), 348$ calcd for $\mathrm{C}_{24} \mathrm{H}_{28} \mathrm{O}_{2}$. Anal. Calcd for $\mathrm{C}_{24} \mathrm{H}_{28} \mathrm{O}_{2}: \mathrm{C}, 82.72 ; \mathrm{H}$, 8.10. Found: $\mathrm{C}, 82.74 ; \mathrm{H}, 8.13$.

The spectral data for various bridged diarylacetylenes, obtained as above or via debromination, are summarized in the Supporting Information.

\section{Acknowledgment}

We thank Petroleum Research Funds, administered by the American Chemical Society, and the National Science Foundation (Career Award) for the financial support.

\section{References}

1(a) Introduction to Molecular Electronics; Petty, M. C., Bryce, M. R., Bloor, D., Eds.; Oxford University Press: New York, 1995. (b) McQuade, D. T.; Pullen, A. E.; Swager, T. M. Chem. Rev. 2000, 100, 2537. 
2(a) Bunz, U. H. F. Chem. Rev. 2000, 100, 1605. (b) Nesterov, E. E.; Zhu, Z.; Swager, T. M. J. Am. Chem. Soc. 2005, 127, 10083. (c) Marsden, J. A.; Palmer, G. J.; Haley, M. M. Eur. J. Org. Chem. 2003, 2355 and references therein.

3Brizius, G.; Billingsley, K.; Smith, M. D.; Bunz, U. H. F. Org. Lett. 2003, 5, 3951.

4Pepermans, H.; Willem, R.; Gielen, M.; Hoogzand, C. J. Org. Chem. 1986, 51, 301.

5)Shukla, R.; Lindeman, S. V.; Rathore, R. J. Am. Chem. Soc. 2006, 128, 5328.

6Bubner, T. P.; Crisp, G. T. Tetrahedron 1997, 53, 11881.

7Spectral data for the isomeric mixture of stilbenophanes $\mathrm{B}$ : $\mathrm{mp} 148-152{ }^{\circ} \mathrm{C} ;{ }^{1} \mathrm{H} \mathrm{NMR}\left(\mathrm{CDCl}_{3}\right)$ ठ 1.56, 1.88, 1.94 (sym m's, 8H), 3.68, 3.85, 3.90 (br t's, 8H), 6.49-7.51 (aromatic/olefinic protons, $20 \mathrm{H}) ;{ }^{13} \mathrm{C} \mathrm{NMR}\left(\mathrm{CDCl}_{3}\right) \delta 26.0,26.1,67.2,68.1,111.4$, $111.8,120.1,120.6,120.8,126.0,126.6,127.1,127.3,127.8,128.16,128.18,128.6$, 129.6, 155.8, 156.9.

8(a) Spectral data for the rearranged acetal $\mathrm{C}$ : $\mathrm{mp} 157-159{ }^{\circ} \mathrm{C} ;{ }^{1} \mathrm{H} \mathrm{NMR}\left(\mathrm{CDCl}_{3}\right) \delta 1.23$ (dd, $J=7.0,1.3 \mathrm{~Hz}, 12 \mathrm{H}$ ), 2.07 (sym m, 4H), 2.84 (septet, $J=7.0 \mathrm{~Hz}, 2 \mathrm{H}), 3.90$ (d, $J=$ $1.3 \mathrm{~Hz}, 4 \mathrm{H}$ ), 3.97 (sym m, 2H), 4.17 (sym m, 2H), $5.38(\mathrm{~d}, \mathrm{~J}=5.8 \mathrm{~Hz}, 1 \mathrm{H}), 5.68$ (d, $J=$ $5.8 \mathrm{~Hz}, 1 \mathrm{H}), 6.75(\mathrm{~d}, \mathrm{~J}=8.5 \mathrm{~Hz}, 2 \mathrm{H}), 6.96(\mathrm{dd}, \mathrm{J}=8.5,2.5 \mathrm{~Hz}, 2 \mathrm{H}), 7.36$ (d, J = 2.5 Hz, $2 \mathrm{H}) ;{ }^{13} \mathrm{C}$ NMR $\left(\mathrm{CDCl}_{3}\right) \delta 24.3,24.5,27.8,33.6,65.4,70.2,106.3,113.4,124.5,127.0$, 131.4, 141.1, 154.5. GC-MS: $\mathrm{m} / z 410\left(\mathrm{M}^{+}\right), 410$ calcd for $\mathrm{C}_{26} \mathrm{H}_{34} \mathrm{O}_{4}$. (b) Formation of Cin eq 5 , at first glance, seems to arise from a pinacol-pinacolone-type rearrangement, which, however, requires an acid catalyst! In another experiment, a NMR spectroscopic analysis of the crude reaction mixture, without using any acid during workup or silica gel chromatography, showed the presence of a similar amount of $\mathbf{C}$, suggesting that $\mathbf{C}$ arises via the rearrangement reaction under basic conditions.

9Mchale, D.; Mammalis, P.; Green, J.; Marcinkiewicz, S. J. Chem. Soc. 1958, 1600.

10Reviews: (a) Kumada, K. Pure Appl. Chem. 1980, 52, 669. (b) Wolfe, J. P.; Wagaw, S.; Marcoux, J.-F.; Buchwald, S. L. Acc. Chem. Res. 1998, 31, 805. (c) Larock, R. C. Adv. Met. Org. Chem. 1994, 3, 97. (d) Larock, R. C. Pure Appl. Chem. 1990, 62, 653. (e) Poli, G.; Giambastiani, G.; Heumann, A. Tetrahedron2000, 56, 5959.

11Search of the Cambridge Crystallographic Database revealed that, in a majority of aryl alkyl ethers, the alkoxy group lies in the aromatic plane. Also see: Schuster, I. I.; Parvez, M.; Freyer, A. J. J. Org. Chem.1988, 53, 5819.

12Compare Brizius et al. in ref 3.

13Hofslokken, N. U.; Skattebol, L. Acta Chem. Scand. 1999, 53, 258-262.

14Simonis, U.; Walker, F. A.; Lee, P. L.; Hanquet, B. J.; Meyerhoff, D. J.; Scheidt, R. J. Am. Chem. Soc. 1987,109, 2659-2679.

15For a similar procedure, see: Rives, J. T.; Oliver, M. A.; Fronczek, F. R.; Gandour, R. D. J. Org. Chem. 1984,49, 1627-1634. 